\title{
How to Achieve a Constructive Alignment, both Ethically and Logistically, in a Curriculum Underpinned by Three Conflicting Education Aims
}

\author{
Elaine Aaltonen \\ University of London, $U K$
}

\begin{abstract}
The purpose of this paper is to outline a study concerning with an improvement initiative collectively idealised by a group of teachers and school middle leaders, assisted by an external consultant, in an educational context in Brazil. It consisted in the design and implementation of a new curriculum for the English as an Additional Language (EAL) classes offered for the elementary school students of a private institution. There was a generalised belief that the curriculum should be simultaneously 'knowledge-and-skills-centred' and 'student-centred' while fostering 'socialisation' when the change was structured. However, when a pilot version of the curriculum started being implemented, at the same time that the main educational leader responsible for its implementation was attending an elective module named Values, Vision and Moral Purpose (VVMP) from the Master's Programme in Applied Educational Leadership at the University of London (UoL), insights gained from a reflection on both theory studied and practice experienced at the workplace led to an understanding that the three education aims contemplated in the curriculum presented flaws, and were incompatible with one another, despite of being valuable. Therefore, it was decided that a study aiming at learning how to interpret and integrate aspects of the three conflicting aims of education, in order to put them into a constructive alignment, both ethically and logistically, would be necessary to ensure a successful implementation of the EAL curriculum. The findings obtained through the study which will be described in this paper were quite helpful for a re-design of the improvement initiative.
\end{abstract}

\section{Introduction}

In 2019, an improvement initiative started being designed within the lower elementary school division of a private school located in a small city close to the capital São Paulo, in Brazil, by a group of English teachers, school middle leaders and an external consultant. It consisted in the creation of a new curriculum to support the EAL classes offered to about five hundred students aged 6-10 years old.

The study group especially created to undertake the initiative decided that the curriculum should be simultaneously 'knowledge-skills-centred' and 'student- centred' while fostering 'socialisation' whilst they were working on its written version.

In the beginning of 2020, when one of the middle leaders was attending the VVMP module offered by the UoL, her attention was drawn towards problems that stem from the fact that these aims present flaws, despite of being valuable. Additionally, she realised that these education aims might also become incompatible with one another when applied in combination, without proper planning, thus undermining the effectiveness of educational institutions.

Besides that, when this leader started working officially as elementary school teacher and coordinator, in the same period, she identified ethical and logistical barriers within her new context. Therefore, she became unsure whether the curriculum would be long-term sustainable, especially in its taught version.

Both conclusion of the curriculum design and its implementation were postponed to 2021 due to the unexpected covid-19 pandemic. Therefore, it was decided collectively that they should discover whether it would make sense to maintain all these aims underpinning the EAL curriculum at the same time as initially planned.

The purpose of this paper is to describe the study carried out, whose objective was increasing overall understanding on how the theories learned would help to interpret and integrate aspects of the three education aims in order to put them into a constructive alignment, both ethically and logistically, focused on leading for learning effectively in the $21^{\text {st }}$ century.

A hybrid set of references supported the analysis, including Egan's [1] article about the tensions in the three distinct and conflicting aims of education; the studies of Coates [2], and Murphy and Torre [3] about school 'Vision, Values and Culture'; and two approaches to ethics studied: 'Deontology' and 'Consequentialism'. Also, insights gained from a critical reading of both Hofstede's 'Cross-Cultural Theory' [4], and the $1^{\text {st }}$ phase of the Project named 'Future of Education and Skills 2030', launched by the Organisation for Economic Co-operation and Development (OECD) in 2015, whose results were released in 2019, were quite relevant.

Findings obtained through this kind of study are important not only to maximise our learning achievements while leading improvement initiatives, such as curriculum design and its implementation, but they are likely to help 
us develop our thinking and enhance our practices in other areas pertaining to educational leadership.

\section{Literature Review}

Egan's [1] article about the tensions in theory, policy and practice around the education aims is insightful. It was opportune to begin drawing the study from it, since the EAL curriculum has been initially conceived to feature the education aims analysed by the author, at the same time, in its written and taught versions.

In a clear and thought-provoking way, Egan [1] explains that thinking on education throughout the $20^{\text {th }}$ century has almost entirely involved only three distinct and conflicting ideas: 'the idea of socialising the young', 'Plato's idea of shaping the mind by a disciplined academic curriculum', and 'Rousseau's idea of facilitating the development of the individual's minds'. He labels education as difficult and contentious because each of these aims is flawed, besides being incompatible with the other two, leading to many problems faced in educational contexts nowadays.

As Egan points out, 'socialisation' was the first education idea, inherited from the hunter-gatherer societies, in which it started being used a long time before the invention of writing. Socialising agents (parents, relatives and friends) used to tell the young hearers stories especially created to transmit a homogeneous image of their society, their individual roles within it, and the larger world around them.

In Native American societies, for instance, stories ranged from origin myths through trickster and hero tales to prophecy, and automatically demanded physical presence, since they were passed along orally; thus, the verbal tradition deeply rooted in close cultural interaction was effective to keep a culture's myths and legends alive within the individual and the community [6].

Broadly defined as "the process by which the individual acquires modes of behaviour and is integrated into society and its social systems through the internalization of norms, values, symbols, customs and patterns of interpretation" [7], the concept of socialisation has remained essentially the same for centuries.

Both story and storytelling are excellent teaching and learning resources, through which we can easily gain the voluntary attention of students to teach them thematic vocabulary and linguistic structures, expound them to scientific, historical, geographic, and cultural backgrounds, in order to expand their understanding of the world, while fostering situations for them to practice and develop a range of skills.

Plato (428 - 348 B.C.), Greek philosopher, prescribed that teaching of culture should begin at home, through the stories parents told their children, stressing the great importance of the content of those stories as first impressions shaping the still malleable minds of children and determining their character [8].

Storytelling with proper content selection should be a crucial part of early childhood education and beyond, since what children learn from the stories they are first told becomes fixed easily and turns into a template for future learning [1], and it fosters children's cognitive and literacy development while forming and informing, entertaining, providing joy and fun. Also, "storytelling helps to internalize the rich fabric of the society and images of the land" [6].

A flaw in socialisation is that it often leads to 'indoctrination', when socialising agents either impose rigidly or persuade their students to accept passively thoughts, ideas, beliefs, values, and patterns of behaviour presented in the stories, rather than teaching them to think critically upon each aspect. The antithesis of education, this practice is common, as "the story orients the emotions of the hearers and so more powerfully shapes their commitments to the values and norms coded within it" [9].

The 'Deontological Ethics', first ethical theory studied, places special emphasis on the relationship between duty and the morality of human actions; and its main exponent is Emmanuel Kant (1724-1804), German philosopher who proposed a sophisticated theory named 'Categorical Imperative', created to tackle indoctrination.

Kant's doctrine is defined as "an objective, rationally necessary and unconditional principle that we must always follow despite any natural desires or inclinations we may have to the contrary" [10]. Yet, indoctrination is not the main threat perceived in the target context, where other ideologies seem more pervasive.

The 'deficit ideology', which is the belief that inequalities result from intellectual, moral, cultural, and behavioural deficiencies assumed, rather than from unjust social conditions such as systemic racism, and economic injustice [among other manifestations of discrimination] [11] is quite threatening. Exemplifying, less than $50 \%$ of the school's inclusion students have what van der Kooij et al. [12] would call their minimal deontological needs attended, such as a qualified intern accompanying them at all times, a customised curriculum, and effective inclusive approaches fostering their integration within their groups.

Regarding the students who follow the regular programme autonomously, their personal and collective development is promoted at a minimal deontological level, since there are rules in place, both established and being applied, towards considering and respecting their thoughts, main needs, feelings, and how certain actions can impact them [12].

Indeed, most people tend to consider teacher's beliefs and attitudes as neutral, thus interpreting them as reflecting traits of their personality or individual values and predispositions. Although many scholars argue that the teacher's ideological orientation is often reflected in his or her beliefs and attitudes, in the way he or she interacts with colleagues at work, treats and teaches students in the classroom [13].

The danger of assuming a deficit ideology in education consists in approaching students and colleagues based upon our perception of their weaknesses instead of their strengths. When a teacher adopts such a perspective, his or her expectations in relation to students will be undermined and his or her ability to recognise both learning
4398 
possibilities and talents will be reduced [14]. Gorski [11] claims that "the most devastating level of such a discriminatory ideology is mistaking difference, particularly difference from ourselves, for deficit”.

The deficit ideology is reflected in talks between teachers, and in their interactions with students with special needs or even some other ones who do not have a psychological or psychiatric disorder, but do need an adapted curriculum too. Sleeter [15] states that "the longstanding deficit ideology still runs rampant in many schools, despite the abstraction that all children can learn".

Alfaro [13] highlights the importance of encouraging the teaching staff to enhance their understanding about their own ideologies, and the links between their ideological stances and their instructional practices.

In sum, this knowledge is relevant to educational theory and practice as it is to philosophy, because extreme or discriminatory ideologies must be avoided by teachers who aim at guarding their own classrooms against practices that may undermine their students' cognitive, affective, and behavioural development [16] .

The deontological approach proposes a reflection about rule-based institutions and their leadership models aiming at investigating whether there is a link between them and the leadership style in place. In the target context, most stakeholders explicitly desire an ethical behaviour permeating all relationships and underlying the actions of staff members towards executing their duties both effectively and ethically. However, there is not a clear ethical perspective in place.

Letwin et al. [17] pose the question "What is the ethical way to behave?" while examining ethical leadership through the lenses of two approaches to ethics: 'Deontology' and 'Consequentialism'. As the authors point out, the deontological approach classifies behaviours into the categories right (ethical) or wrong (unethical) whereas the consequentialist ethics has in its premise that no action can be declared ethical or unethical without considering the results. They also remind that the Utilitarian version of Consequentialism calls for examining the results of various behaviours to determine which one(s) will lead to 'the greatest good to the greatest number of people'.

In our institution, staff members with different ideologies, personal goals, and approaches to ethics are in constant dispute to defend their points of view. The school senior leadership is in the middle of this tension doing predominantly what is "good" rather than what is "right". Stakeholders including some middle leaders and a large number of teachers and parents perceive leadership's effectiveness as deontological in the ethical sense, namely reflecting principled behaviour such as being fair to others, honest with and dedicated to followers [18].

Nevertheless, the strength of the senior leader in charge of the lower elementary school division lies in her charisma, excellent interpersonal relationship skills, and efficacy in delegation, but her conduct in the ethical sense is not inspiring. An essential role in framing and sharing the institution's vision, values and culture through a clear and effective communication across school is not played.
Brown et al. [18] define ethical leadership as "the demonstration of normatively appropriate conduct through personal actions and interpersonal relationships, and the promotion of such conduct to followers through two-way communication, reinforcement and decisionmaking", and argue that ethical leaders are believed to possess high levels of character and integrity, which dispose them to do the "right" thing or otherwise act in accordance with moral rules.

Another flaw inherited from the hunter-gatherer societies is 'the oppositional thinking', which sets people against each other in greater or lesser degree. Egan [1] reminds that, "for hunter-gatherers, the difference between we and they consisted in treating 'the recognized faces' as friends, and 'the unknown' as potential enemies who should be killed".

The ethical dilemma of 'they' caused by a culture of 'we/they' can impact thinking and action to the extent that these people's minds will not enable their engagement in common goals when confronted with new or innovative propositions coming from an outsider's perspective.

Oppositional thinking is another local ethical barrier, potentialized by the context's high Power Distance culture according to Hofstede's [4] Cross-Cultural Theory. Insights learned from his studies on how values in the workplace are influenced by culture have been helpful.

Through his research, he demonstrated that values which distinguish cultures could be statistically categorized into groups which include 'Power Distance'. Known as 'Hofstede's Cultural Dimensions', these groups help to identify cultural characteristics that are not perceived rationally at work. 'Power Distance' deals with the fact that all individuals in societies are not equal, expressing the attitude of the culture towards these inequalities amongst individuals.

With a score of 69 , Brazilian society reveals a belief that hierarchy should be respected, and inequalities amongst people accepted. In corporate environments, there is commonly one leader who is expected to protect his or her followers in exchange of loyalty and is responsible for everything. Aware of these cultural characteristics, the leader tends to become more assertive in helping the teachers perceive the importance of being co-responsible for their actions, for example.

Known as the idea of a disciplined academic curriculum, the second education aim was inherited from Plato, whose thought on education was developed in his two largest works: 'The Republic' and 'The Laws'. Havelock [19] argues that 'Plato's greatest achievement was to work out how to think once alphabetic literacy became common". Other scholars like Hummel [20] have acknowledged Plato's innovative ideas, including equal rights for both men and women to attend school; compulsory schooling for all, far beyond of an elementary education; as well as his initiative of designing a complete education system, covering every aspect from its administration to a detailed curriculum.

'Literacy' was the invention that boosted human intellectual progress after the development of language, allowing generations of people to record their knowledge 
and experience. "The vast array of knowledge and human experience stored has enabled our minds to transcend in our time, place, and circumstances" [1].

The invention of writing allowed thoughts to start being captured and to live on. Ong [21] claims that writing has transformed human consciousness more than any other invention, and claims that "without writing, the literate mind would not think as it does, not only when engaged in writing, but when composing its thoughts in oral form".

Nevertheless, due to the large amount of accumulated knowledge, many educators find difficult to determine 'the best knowledge for children to learn', which Egan considers a flaw related to the second education aim. In the target setting, the difficulty in selecting good content for the EAL curriculum is a logistical barrier rather than a flaw.

One of the main challenges to overcome consists in managing our time and resources effectively, improving our work conditions, and implementing a successful Continuing Professional Development (CPD) Programme in order to be able to meet the different demands, both as teachers and educational middle leaders, who have a heavy workload and are part of a reduced workforce.

The third education aim is attributed to Jean-Jacques Rousseau (1712-1778), a Genevan philosopher whose ideas about education were mainly developed in his novel Emile. His main idea was that "education should be carried out, so far as possible, in harmony with the development of the child's natural capacities" through a process of apparently autonomous discovery, in contrast to a model of education in which the teacher is a figure who conveys knowledge and skills according to a preestablished curriculum [10].

Rousseau argued that human beings had a nature and a natural process of development that should be disclosed through careful observation aided by reason, and his progressist educational ideal have made a profound impact in modern educationalists, thus in educational theory and practice, while leading us to polemical battles between supporters of 'student-centredness' against 'subject-andskills-centredness', i.e. between progressists and traditionalists.

The flaw worthwhile highlighting was pointed out by Egan [1] as "the large number of regularities in human mental development, intrinsically attached with social experience, culture, and other intellectual tools", making hard to identify whether they result from human nature, social, cultural, or intellectual tools.

$\mathrm{He}$ argues that the difficulty to measure these regularities, which differ enormously from individual to individual, and determine whether they result from our nature or an autonomous developmental process was also identified by Vygotsky as a flaw in Piaget's [22] 'Theory of Cognitive Development'.

In his theory, Piaget aimed at understanding the nature of intelligence, and how children acquire knowledge, concluding that children pass through four different stages of mental development as a biological process that occurs due to maturation and contact with the environment [22].
Unlike Piaget's notion that the development of children should necessarily precede their learning, Vygotsky [23] believed that social learning tended to precede development: "Learning is a necessary and universal aspect of the process of developing culturally organised, specifically human psychological function".

Thus, Vygotsky's 'Sociocultural Theory of Cognitive Development' [23] stresses the fundamental role of social interaction in the development of cognition as he believed that community plays a central role in the process of making meaning.

Our institution is highly influenced by Rousseau's thought on education, as well as by insights from Piaget's and Vygotsky's theories.

Furthermore, it is important to highlight that it was valuable for the three-fold analysis of education aims the vision recently built collectively by representatives from several countries alongside the OECD about how the education systems could be effectively improved in the $21^{\text {st }}$ century, mainly in respect with curriculum (re)design and with setting out a conceptual framework for learning.

\section{Insights from the 'OECD Future of Education and Skills 2030' Project}

As a response to the current demands by societies for improvement of the education systems, in 2015 the OECD launched the 'Future of Education and Skills 2030' Project, aiming at helping countries to prepare their education systems for the future.

In its first phase (2015-19), the project focused on determining the set of competencies (knowledge, skills, attitudes and values) that today's students should have or develop in order to thrive in 2030 and beyond.

An article recently published by the OECD outlining the project provides good insights for the design and implementation of curricula targeting all the phases of schooling, based on the premise that "every learner, no matter his or her age or background, can develop as a whole person, fulfil his or her potential, and participate in shaping a future that improves the well-being of individuals, communities and the planet" [5], although the project focuses on secondary education as a starting point.

Policy makers, researchers, school leaders, teachers, students and social partners from around the world have developed with the OECD a vision of education and a learning framework that sets out three key competencies which should be contemplated in contemporary curricula (see Table 1).

Table 1. OECD Key Competencies

\begin{tabular}{|c|c|}
\hline Competencies & The Ability to \\
\hline & $\bullet \quad$ use language, \\
& symbols and \\
& text \\
& interactively \\
& $\bullet \quad$ use knowledge \\
Use tools interactively & and \\
\hline
\end{tabular}




\begin{tabular}{|c|c|}
\hline & $\begin{array}{ll}\text { information } \\
\text { interactively } \\
\text { - } \quad \text { use technology } \\
\text { interactively }\end{array}$ \\
\hline $\begin{array}{l}\text { Interact in heterogeneous } \\
\text { groups }\end{array}$ & 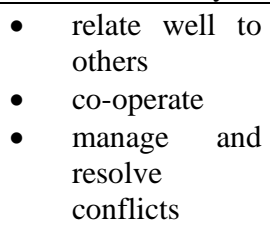 \\
\hline Act autonomously & 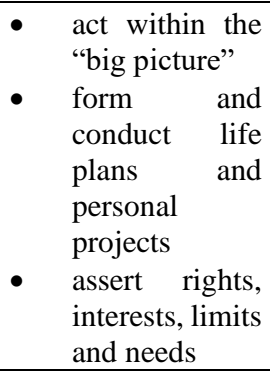 \\
\hline
\end{tabular}

The OECD Learning Framework uses the metaphor of the 'learning compass' (Figure 1) to demonstrate these competencies that students need in order to navigate towards the future we want, individually and collectively [5].

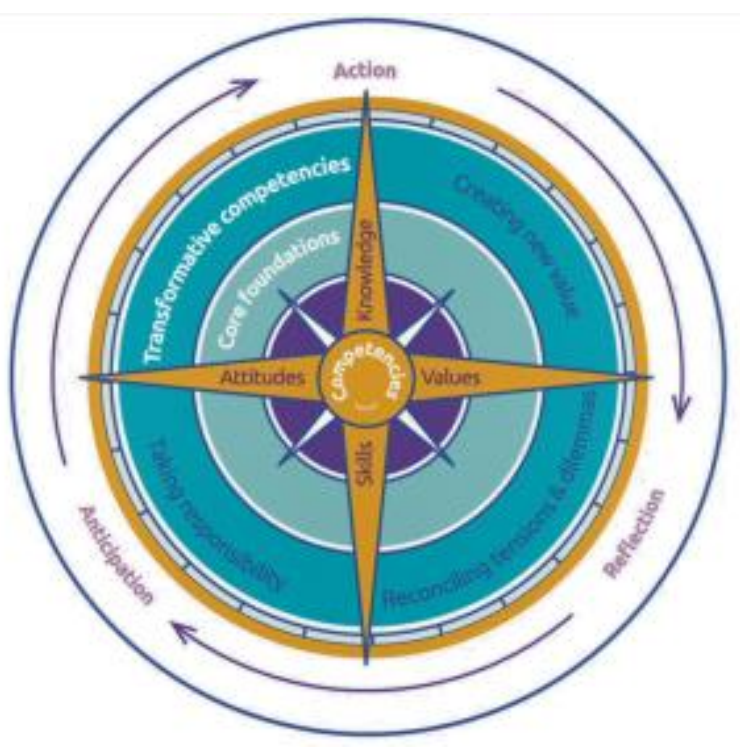

Figure 1. OECD Learning Compass 2030

In addition to the three key competencies, other innovative ideas pointed out in this project include the following:

- Approaches to curriculum design and learning progression have been changing from a 'static, linear learning-progression model' to a 'nonlinear, dynamic model', by recognising that each student has his/her own learning trajectory and is equipped with different prior knowledge, skills and attitudes when he/she starts school;
- Student assessment has shifted from standardised testing to different types of assessments for different purposes;

- The role of students has been evolving from participants in the classroom by listening to directions of teachers with emerging autonomy to active participants with student agency or coagency, who also shape the classroom environments.

A critical reading of 'The OECD 2030' Project reinforced the importance of giving a centrality to the student-centred aim as a means to ensure a high-quality, ethical and values-driven education for all and for each individual at the same time, whilst pursuing the constructive alignment of education aims.

\section{Discussions}

At this point it is important to make some considerations. First, Egan's critiques of the education aims do not simply reflect his refutation to the educational system, but nonconformity with the problems that we have faced for using these aims as analytical tools, and with our negligence in dealing with these issues. Biesta [24] also criticises these aims for the same reasons, arguing, for instance, that academic knowledge kept apart from socialisation and individuation is useless.

Second, a critique about Egan's article is that he fails in recognising that the cultural aspect can impact both processes of thinking on and making education. He does show that the idea of socialisation works against cultural diversity, stating why this aim fits better small societies, but his interpretation about the development of human brains tends to promote homogeneity in thinking about possible responses, and he unfortunately does not consider that 'intercultural dialogue' can powerfully foster thinking and learning.

Third, one of the most relevant insights gained through this three-fold analysis of aims was the confirmation that the best way to place the three education aims into a constructive alignment within the target context will be through exploring the existing links between them [25].

As a matter of fact, the most relevant link consists in enabling the teaching and learning processes of formal knowledge to take place within meaningful real-world contexts, carefully planned to foster the individual development of our students, through providing them with valuable learning experiences as key for the successful implementation of the EAL curriculum.

Additionally, 'vision' is a crucial element for the success of our improvement initiative. Murphy and Torre [3] unpack vision into three distinct but related domains: mission, which addresses overarching values and purposes; goals, which provide direction; 
expectations, which establish specific targets; whilst Coates [2] sees 'vision' as a process involving staff, parents and governors that should remain under regular shared review to continuously impact organisation change and improvement.

The fact is that vision is essential for the improvement of educational institutions [3], so visionbuilding is a central aspect of leading for success, defined in terms of providing students with meaningful learning experiences. Through reviewing and expanding our knowledge about these concepts, and affording them a centrality, they will likely become a reference point for strategic intent, decision-making, evaluation and organisational dialogue [2].

Figure 2 was created by the author to illustrate how the constructive alignment of the three education aims could be achieved, enabling us to build and implement an ethical, values-driven, and high-standard EAL curriculum.

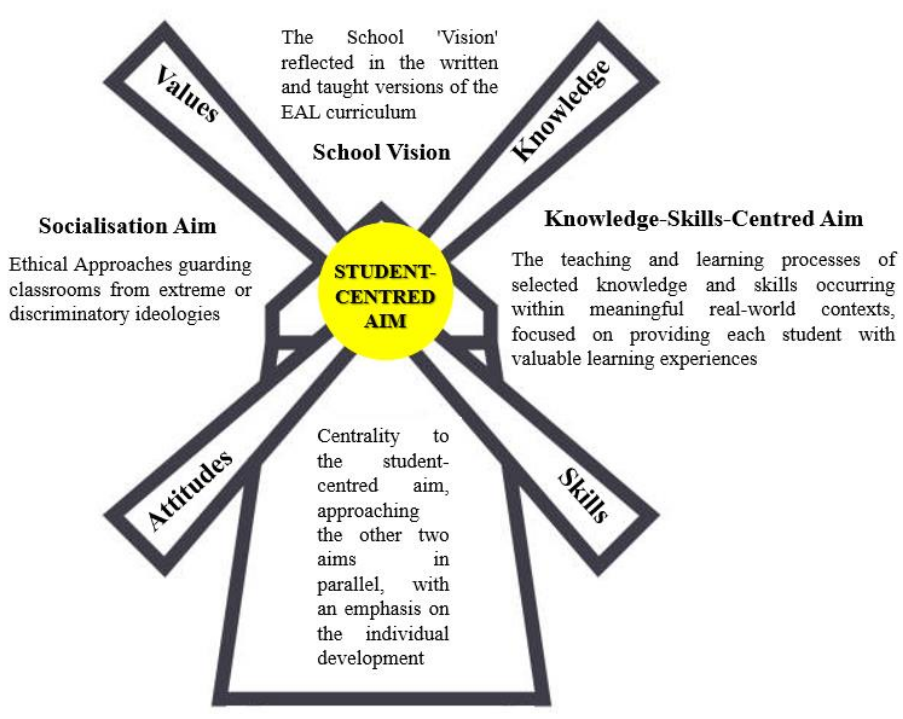

Figure 2. Constructive Alignment of the Education Aims

The symbology underlying the image of the windmill is of life, serenity, resilience, self-sufficiency, and perseverance in a harsh environment. It is impressing that not only does a windmill remain intact within a fierce storm, but it most likely enjoys a good strong wind.

Metaphorically, a person who is equipped with a proper set of knowledge, skills, values and attitudes will likely find easier to overcome challenges or problems in an unpredictable future, and will likely have maximised the chances to transform the world, sometimes dangerous and hostile, into a better place, even being able to discover new possibilities of well-being and growth.

It is relevant to emphasise that the study outlined in this paper is in line with current education thinking and trends disseminated through works such as OECD's 'The Future of Education and Skills 2030' Project.
At last, the efficacy of both middle and senior leadership is of most relevance too, in playing roles which include articulating the whole initiative, mobilising people and resources, leading by example in order to inspire colleagues, and fostering an effective communication across the entire school.

\section{Conclusion}

This study helped to enhance our understanding on how to achieve a constructive alignment, both ethically and logistically, between the three education aims, as a means to contribute to the success of the improvement initiative.

It is pertinent to maintain the three aims underpinning our EAL curriculum at the same time, as initially planned, since they are valuable despite the flaws they may present.

Towards fostering a constructive alignment, important actions to be taken will include: giving a centrality to the student-centred aim, whilst the other ones (knowledgeskills-centredness and socialisation) will be approached in parallel, with an emphasis on the individual development, enabling the teaching and learning processes of selected knowledge and skills to occur within real-world settings, carefully planned, thus meaningful for each student, which will likely lead to valuable and effective learning experiences for all; ensure that the vision, values and culture of the institution be reflected in both written and taught versions of the EAL curriculum; and promote the continuing professional development of teachers and leaders.

Ultimately, the success of the improvement initiative will rely on the efficacy of its middle leadership in orchestrating everything, and on the support by the senior leadership and other stakeholders involved.

\section{References}

[1] Egan, K. (2001). Why Education is So Difficult and Contentious. Teachers College Record, Vol. 103, pp.923941, Copyright by Teacher College, Columbia University.

[2] Coates, M. (2017). Setting Direction: Vision, Values and Culture. School Leadership and Education System Reform, Chapter 8, London, Bloomsbury.

[3] Murphy, J. and Torre, D. (2015). Vision: Essential Scaffolding. Educational Management Administration and Leadership, Vol. 43, Issue 2, pp.177-197.

[4] Hofstede, G. (1986). Cultural Differences in Teaching and Learning. International Journal of Intercultural Relations; Vol. 10; pp. 301-320, Copyright Pergamon Journals Ltda.

[5] OECD. (2019). Future of Education and Skills 2030. OECD Learning Compass 2030. Copyright OECD, pp. 3150, URL: http://www.oecd.org/. (Access date: 10 May 2020). 
[6] Celi, A. and Boiero, M. (2002). The Heritage of Stories: A Tradition of Wisdom. Mid-America American Studies International, Vol. 40, No.2, pp. 57-72.

[7] Dijkstra A. and Motte, P. (2014). Social Outcomes of Education. The assessment of Social Outcomes and School Improvement through School Inspections. Amsterdam University Press.

[8] Hummel, C. (1994) Plato. Prospects: The Quarterly Review of Education, Vol. 24, No. 1-2, 1994, p. 329-342, UNESCO, Paris, URL: http://www.ibe.unesco.org/en/resources/prospectsquarterly-review-comparative-education. (Access date: 9 May 2020).

[9] Egan, K. (1988). Primary Understanding: Education in Early Childhood. New York: Routledge.

[10] The Stanford Encyclopaedia of Philosophy. (2020). The Metaphysics Research Lab, Center for the Study of Language and Information (CSLI), Stanford University, Library of Congress Catalog, Data: ISSN 1095-5054, U.S.A., URL: https://stanford.edu/. (Access date: 9 May 2020).

[11] Gorski, P. (2010). Unlearning Deficit Ideology and the Scornful Gaze: Thoughts on Authenticating the Class Discourse in Education, Vol. 402, pp. 152-173, Peter Lang, URL: http://www.jstor.org/stable/42981081. (Access date: 17 May 2020).

[12] Kooij, J. Van der, Ruyter, J. and Miedema, S. (2015). The Influence of Moral Education on the Personal Worldview of Students. Journal of Moral Education, Vol. 43, No. 3, pp. 346-363.

[13] Alfaro, C. (2008). Developing Ideological Clarity: Unmasking the Trap of Teacher Neutrality, New York: P. Lang;

[14] Ford, D., and Grantham, T. (2003). Providing access for culturally diverse gifted students: From deficit to dynamic thinking. Theory into Practice, Vol. 42, No. 3, 217-225.

[15] Sleeter, C. (2004). Context-Conscious Portraits and Context-Blind Policy. Anthropology \& Education Quarterly, Vol. 35, No. 1, pp. 132-136, Washington DC: AERA.

[16] Phillips, D. (2014). Encyclopedia of Educational Theory and Philosophy. Foundations of Education. Sage Publications.

[17] Letwin, C., Wo, D., Folger, R., Rice, D., Taylor, R., Richard, B. and Taylor, S. (2015). The Right and the Good in Ethical Leadership. Journal of Business Ethics Vol. 137, No. 4, pp. 743-755.
[18] Brown, M., Treviño, L., \& Harrison, D. (2005). Ethical leadership: A Social Learning Perspective for Construct Development and Testing. Organizational Behavior and Human Decision Processes, Vol. 97, pp. 117-134.

[19] Havelock, E. (1986). The Muse Learns to Write: Reflections on Orality and Literacy from Antiquity to Present. Vail Ballou Press, Binghamton, NY.

[20] Hummel, C. (1999). Collected Dialogues of Plato, edited by E. Hamilton and H. Cairns, Princeton, N.J., Princeton University Press.

[21] Ong, W. (1982). Orality and Literacy: The Technologizing of the Word. New York: Methuen.

[22] Piaget, Jean. (1972) Os Estágios do Desenvolvimento Intelectual da Criança e do Adolescente. In.: Piaget. Rio de Janeiro: Forense, pp. 4-16.

[23] Vygotsky, L. S. (1978). Thought and Language, Cambridge, MA: MIT Press. (Original work published in 1934).

[24] Biesta, J. J. (2006). Beyond Learning: Democratic Education for a Human Future. Paradigm Publishers, Boulder, CO.

[25] Higham, R. (2020). Critiques of Egan's article: Tutor's response, MA in Applied Educational Leadership: VVMP module, Forum 1, 20 January 2020. 